Tema central

Wiley Ludeña*

\title{
Ciudad y patrones de asentamiento. Estructura urbana y tipologización para el caso de Lima
}

\begin{abstract}
Lima's conversion in an object of historic inquiry was produced in the middle of the 19th century, under the form of literary chronicles or positivist descriptions of reality. Instead the transformation of Lima's metropolis in an object of investigation aiming for the theoretical modeling of reality is barely a phenomenon of the last 50 years. The following text deals with the proposals of records formulated in order to reveal some constants and formation laws concerning the growth and socio-spatial structure of Lima city. The basic tendencies and aspects of reference concerning the city are defined.
\end{abstract}

Key words: Lima, urban thought, theoretical models, urban structure, socio-spatial segregation, urban planning traditions.

\section{Resumen}

La conversión de Lima en objeto de indagación histórica se produjo desde mediados del siglo XIX bajo la forma de crónica literaria o descripción positivista de la realidad. En cambio, la transformación de la metrópoli limeña en objeto de investigación con fines de modelamiento teórico de la realidad es apenas un fenómeno de los últimos 50 años. El presente texto se ocupa del registro de todas aquellas propuestas formuladas con el objetivo de revelar algunas constantes y leyes de formación sobre el crecimiento y la estructura socio-espacial de la ciudad de Lima. Se definen las tendencias básicas y ámbitos de referencia en la ciudad.

Palabras claves: Lima, pensamiento urbano, modelos teóricos, estructura urbana, segregación socio-espacial, tradiciones urbanísticas. 
Wiley Ludeña

\section{A modo de introducción}

$\mathrm{L}$ a conversión de Lima en objeto de discurso historiográfico se produjo desde mediados del siglo XIX bajo la forma de crónica literaria o descripción positivista de la realidad. Esta es la Lima evocada por viajeros como Robert Proctor, Leonce Angrand, Robert Krause, E.W. Middendorff o Max Radiguet, entre otros. Pero también es la ciudad de los primeros estudios, como los realizados por José María Córdova y Urrutia y su Estadística histórica, geográfica, industrial y comercial de los pueblos que componen las provincias del departamento de Lima (1839), o por Manuel A. Fuentes y su célebre Lima. Apuntes históricos, descriptivos, estadisticos y de costumbres (1867).

En cambio, la transformación de la metrópoli limeña en objeto de investigación con fines de modelamiento teórico de la realidad es apenas un fenómeno de los últimos 50 años. Período relativamente corto, pero significativo por la serie de planteamientos formulados desde diferentes perspectivas disciplinares y distintos niveles de profundidad.

Los primeros esfuerzos por sistematizar las estructuras que caracterizan el funcionamiento socioespacial de Lima se encuentran en formulaciones de la primera mitad del siglo XX, como la de Ricardo Tizón y Bueno en su libro El plano de Lima. Apuntaciones históricas y estadísticas (1916). Asimismo, en la propuesta de la "Gran Lima" esbozada en 1927 por el arquitecto alemán Werner Lange a solicitud del gobierno de entonces, así como en las formulaciones del ingeniero Alberto Alexander referidos a las relaciones entre ciudad y habitación en su estudio Estudio sobre la crisis de la habitación en Lima (1922).

En todos estos casos, las interpretaciones del proceso urbano limeño aparecieron ya sea como formas intuitivo-empíricas de sistematización o como subproductos condicionados por exigencias de orden proyectual, de gestión urbana o de un registro del valor del suelo urbano vinculado a los intereses del negocio inmobiliario.

\footnotetext{
Universidad Nacional de Ingeniería-Universidad Ricardo Palma. Director revista ur $\{b\}$ es. E-mail: wludena@uni.edu.pe
}

Las primeras aproximaciones basadas en la aplicación sistemática de teorías urbanas y métodos preestablecidos de lectura de la ciudad, tendrían lugar en el marco de las investigaciones iniciales promovidas por la Oficina Nacional de Planeamiento y Urbanismo (ONPU, 1949a y 1949b), creada en 1946. Posteriormente, la propuesta del geógrafo John P. Cole, en 1957, se encargaría de marcar otros parámetros de interpretación. Como culminación efectiva de este período fundacional, puede mencionarse al documento y propuesta tipológica encarnada por el Plan de Desarrollo de Lima-Callao a 1980 (PLANDEMET), formulado en 1967 (ONPU, 1967). Las propuestas que se desarrollarán a partir de la década del setenta significaron no sólo una mayor depuración de lo formulado anteriormente, sino el develamiento más preciso de una realidad y dinámica urbanas más compleja y contradictoria.

\section{Ciudad y estructura. Primeras propuestas}

\subsection{La estructura de barrios del "área metropolitana" según la ONPU}

Como parte de los estudios de base desprendidos de la formulación del Plan Piloto de Lima de 1949, la ONPU estableció una clasificación de las distintas formas de ocupación del "área metropolitana", basada fundamentalmente en los análisis de los aspectos físico, económico y social de las viviendas insalubres (ONPU, 1949a y 1949b). La clasificación vendría a ser el primer esquema de estas características formulado para el caso de Lima.

Bajo una caracterización general del territorio metropolitano en dos grandes áreas -la central y la urbana-, el esquema propuesto identifica cinco tipos de barrios o formas de ocupación del suelo (ONPU, 1955). Estos son los siguientes:

- Barriadas. Barrios formados sobre tierras invadidas, no conformados en arreglo a un plan preconcebido; si este existe, es muy rudimentario. Carecen de los servicios públicos y sociales más elementales y presentan las peores condiciones de salubridad ambiental.

Barrios incompletos. Barrios de trazado elemental que cuentan con servicios incomple- 
tos y una mayoría de viviendas sin terminar, construidas en gran parte por los mismos pobladores. Cuentan escasamente con servicios sociales y comunales. Existen dos subgrupos: a) barrios incipientes, con gran actividad constructiva, densidad relativamente baja y servicios públicos inexistentes; $\mathrm{yb}$ ) barrios estacionarios, en los cuales no se distingue mayor actividad constructiva y abundan las construcciones multifamiliares en forma de callejones o corralones, con graves cuadros de promiscuidad.

- Barrios decadentes. La mayor parte están ubicados en la zona más antigua de la urbe. Sujetos a una explotación cada vez más intensa, sin recursos para su reparación y caracterizados por el abandono, presentan agudos indicios de hacinamiento, promiscuidad, delincuencia, morbilidad, etc. Se distinguen dos subgrupos: a) barrios de vivienda subdividi$\mathrm{da}$, con preeminencia de la antigua casona residencial española, convertida en vivienda multifamiliar; y b) barrios de casas de vecindad, con predominio de viviendas multifamiliares construidas en forma de callejones de uno o varios pisos, que poseen sucesivas subdivisiones y se encuentran en constante abandono. Estas edificaciones se han convertido en tugurios sumamente peligrosos.

- Barrios modernos insalubres. Se distinguen dos subgrupos: a) Tipo l, de gran densidad y totalmente construidos, tienen gran difusión en La Victoria; y b) Tipo II, con edificaciones de un máximo de tres pisos, y la mayor parte, de construcciones de uno y de dos pisos.

- Barrios en buen estado. En estos se pueden distinguir varias categorías de densidad: a) alta, con abundancia de edificios de departamentos con ascensor; b) media, con casas de uno y de dos pisos; y c) barrios-jardín, con casas de uno y de dos pisos y abundantes áreas de jardines.

Esta tipologización de los barrios puede resultar limitada, toda vez que como sus propios autores lo señalan, se reduce básicamente a identificar los casos de aquellos barrios donde las condiciones de la vi- vienda resultan insalubres. Tal vez este hecho explique por ejemplo por qué el ámbito de los "barrios en buen estado" no haya merecido una mayor especificación más allá de su caracterización por el factor de densidad. Por otro lado, se trata de un esquema en el cual las variables e indicadores empleados no resultan uniformes en su aplicación en uno u otro caso.

Este planteamiento de la ONPU se convertiría en cierto modo en un esquema base para el desarrollo de posteriores propuestas. Este es un atributo indiscutible. Tal como ocurriría por la misma época -la década de los cincuenta- con formulaciones como la de Matos Mar (1958 y 1977) y su esquema de tipologización de la barriada limeña; la de Cole (1957) y su afán de establecer una relación entre ciudad y estructuras morfológicas; y la de Córdova (1958) y su clasificación de tipos de barrios en función de las condiciones de la vivienda.

\subsection{La estructura de la "gran Lima"}

Contratado por la ONPU para coadyuvar con la realización del Plan Regulador de Lima, John P. Cole, geógrafo de la Universidad de Nottinghen (Inglaterra), publicó en 1957 su Estudio geográfico de la gran Lima. En este puede encontrarse uno de los primeros intentos de vincular cada etapa del desarrollo histórico con una sistemática a aquellos rasgos característicos de la estructura urbana y la forma de la ciudad de Lima.

En relación a la "forma del área urbana" de Lima, Cole encuentra que la ciudad tiene una forma mixta, combinando al mismo tiempo la forma de las urbes cuya expansión está fuertemente condicionada por una geografía irregular ${ }^{1}$. La combinación entre terrenos llanos y barreras geográficas configura el escenario que da sentido a la forma de Lima. El autor sostiene que hacia el Oeste y el Sur, la costa no permite una expansión más allá de ocho a 12 kilómetros desde el Centro. Al Norte, el lecho del río Rímac constituye un obstáculo para la expansión en dicha dirección. Al Norte y al Este, se encuentra una cadena de cerros de pendiente elevada, los cuales confor-

Aquellas ciudades ubicadas en territorios relativamente llanos y sin accidentes pueden expandirse en todas las direcciones y mantener una forma más o menos regular, como es el caso de Milán, Roma, París y Londres (Cole, 1957). 
man asimismo barreras que limitan una expansión regular. Debido a estas características, y a la existencia de una amplia zona llana, el desarrollo de Lima ha sido irregular. $\mathrm{O}$, propiamente, una combinación entre una forma regular e irregular.

$\mathrm{Al}$ ser Cole un geógrafo, su visión de la forma de la ciudad no puede estar ajena a este hecho. Sin embargo, lo trasciende para adentrarse en la formulación de uno de los primeros intentos de sistematización morfológica del tejido urbano de Lima, basada en referencias de orden empírico pertinentes a la propuesta. En este sentido, se distinguen hasta cuatro formas de trazado urbano en función de la orientación de las calles.

En el primer caso, se trata de la "cuadrícula ortodoxa”, tal como queda expresada en la traza fundacional del llamado Damero de Pizarro. Pero esta característica también es descubierta en lo que el autor denomina los "distritos modernos", como La Punta o La Victoria, los cuales por esta razón son esencialmente monótonos y carecen de valor artístico.

En el segundo caso, se trata de una traza menos regular, constituida por calles que en algunos casos se cortan en sentido oblicuo. Esta estructura se registra básicamente en las zonas de expansión producidas entre los siglos XVII y XVIII. Actualmente, las zonas de Barrios Altos y el Sur de La Colmena tienen estas características.

El tercer tipo de traza se refiere a la de los barrios planificados, como la Unidad Vecinal No 3 y Piedra Liza. En ambos casos se trata de un esquema moderno que contiene una jerarquía de vías en función de las necesidades del peatón y el tránsito automotor.

El cuarto tipo tiene relación con la existencia de las "barriadas clandestinas". En este caso hay dos subgrupos. El primero se refiere a la traza de las barriadas ubicadas en los cerros de San Cosme, Leticia, El Agustino y Santa Rosa. Aquí se percibe una trama totalmente irregular con ausencia de calles y constituida básicamente de senderos y escaleras que siguen la orientación de los accidentes morfológicos del cerro. En el segundo subgrupo están las barriadas ubicadas en la parte llana de la ciudad. En este caso, la traza resulta más regular y previsible en términos morfológicos.
Para Cole, Lima es una ciudad que está en una fase de plena evolución. Por lo tanto, no es posible advertir aún una serie de rasgos definitivamente constituidos. Sin embargo, sostiene que, en relación al crecimiento de Lima y la constitución de las "zonas funcionales", existen dos tendencias evidentes. La primera alude al desarrollo de una "centralización externa" de las funciones políticas, comerciales e institucionales en el área central de la ciudad, y trae como consecuencia que las áreas periféricas tengan sólo una vocación eminentemente residencial. La segunda tendencia se refiere a la ubicación exterior de muchas funciones, generando así que la ciudad tenga una forma muy extendida. En este caso se menciona la extensión y la forma del aeropuerto de Limatambo, así como la franja de cerca de 11 kilómetros de la zona industrial de la avenida Argentina (Cole, 1957).

La propuesta de Cole se complementa con la identificación de las distintas áreas de Lima en función de otras variables, como las condiciones de la vivienda o la implantación de las funciones militares y religiosas, entre otras. Si bien en muchos sentidos se trata de una propuesta todavía esquemática y basada en una descripción simplificada de algunos datos, su importancia estriba en el esfuerzo por construir una nueva armazón con aquellos rasgos que constituyen la realidad urbana de Lima, y que hasta entonces habían sido asumidos de modo general y arbitrario.

\subsection{El Plandemety los "Patrones de asentamiento" de Lima}

En la historia de la planificación urbana peruana, luego del Plan Piloto de Lima de 1949, el Plan de Desarrollo de Lima y Callao a 1980 (PLANDEMET) aprobado en 1967, constituye un auténtico hito de referencia. No sólo porque se trata de un destacado esfuerzo por formular un plan urbano basado en una visión sistémica de la ciudad y estudios multidisciplinarios, sino también porque su formulación implicó la creación del espacio y laboratorio de síntesis más importante para la naciente planificación urbana peruana.

La investigación de base que fundamentaría luego al PLANDEMET significó una auténtica bisección de la realidad urbana limeña, como nunca 
había sido hecho en el Perú. Entre los estudios específicos, uno que destaca en particular fue el que propuso una tipologización morfológica de los distintos modos de ocupación y construcción de la urbe limeña.

$\mathrm{Al}$ respecto, los autores del PLANDEMET consiguen identificar cuatro tipos de áreas, en las cuales es posible advertir una lógica particular de implantación residencial y morfológica. Estas cuatro áreas que definen a grandes rasgos la fisonomía de Lima Metropolitana, son las siguientes: a) las áreas nucleares; b) el anillo extranuclear; c) las áreas periféricas al casco urbano, y d) las áreas corredor de los asentamientos nucleares (ONPU, 1967).

Las “áreas nucleares" representan las zonas centrales de residencia de los primeros y principales agrupamientos de vivienda del área metropolitana: Lima, el Callao y Miraflores. Estas sufren un proceso de expulsión de la función residencial por la comercial. El tipo de patrón residencial es el que corresponde a la vivienda decadente, con una alta densidad y acentuado deterioro.

El “anillo extranuclear" está constituido por áreas residenciales implantadas en torno a las nucleares, y se originan por el efecto centrífugo de expulsión de la función vivienda que se produce en estas áreas nucleares. Existen dos formas de anillos extranucleares en función de la mayor o menor distancia del centro. El primero, contiguo al centro, y el segundo, que delimita el exterior del casco metropolitano. Entre estos dos extremos se localizan hasta tres tipos de áreas residenciales: heterogéneas, en transición y homogéneas.

Las “áreas periféricas al casco urbano”, el tercer ámbito de características morfológicas definidas, se constituye de asentamientos residenciales ubicados fuera de los linderos físicos del casco propiamente dicho, cuya implantación presenta generalmente condiciones de solución de continuidad con el área consolidada. Un rasgo característico de los asentamientos ubicados en esta área es su diversidad y diferencias de calidad ambiental. Este hecho se produce por otro rasgo característico de las áreas periféricas: la instalación tanto de la población de niveles económicamente altos, así como de los estratos de población económicamente bajos. Sin embar- go, pese a esta diferencia, existen algunos elementos comunes. Entre ellos se puede mencionar la baja densidad existente, tanto en las urbanizaciones como en las barriadas.

Finalmente, la cuarta área corresponde a las “áreascorredores de los asentamientos nucleares”. No se trata precisamente de una nueva área de expansión, sino del cambio de uso y estructura morfológicas que viene produciéndose en las zonas que sirven de conexión a las áreas nucleares, como es el caso de las avenidas Arequipa, Brasil y Petit Thouars. En estas zonas viene produciéndose una mayor densificación constructiva, producto tanto de la construcción de edificios de departamentos y oficinas, como de centros comerciales.

Cada una de estas áreas presenta a la vez una serie de semejanzas y diferencias en relación a la lógica de implantación de la vivienda, en términos cualitativos y cuantitativos. Al respecto, el estudio de PLANDEMET resume la existencia de cinco patrones de asentamiento residencial: incipiente, decadente, en transición, en consolidación y consolidado.

Cada uno de estos cinco patrones representan “áreas uniformes de vivienda" en la medida de la preponderancia de un tipo de vivienda, de calidad, de distribución o de densidad. La caracterización de cada de uno de estos se basa en un análisis global de la situación de la vivienda, ya sea desde el punto de vista físico (área del lote, materiales de construcción, estado de conservación, servicios, etc.) y el tipo de diseño, así como de la densidad registrada y la existencia de factores ambientales condicionantes (industria y comercio). Sin embargo, el criterio de diferenciación más importante fue el análisis de la "dinámica de cambio", a través del uso de indicadores como el referido a los edificios de propiedad horizontal, la edad de la construcción, el grado de hacinamiento habitacional, los niveles de concentración y dispersión, la existencia de callejones, tugurios y casas de vecindad o la presencia de elementos ajenos a la vivienda y la apertura de nuevas vías, entre otros (ONPU, 1967).

El estudio del PLANDEMET estima que el $46,9 \%$ de la población se concentra en áreas de alta densidad, mientras que el 5,2\% lo hace en áreas de muy alta densidad. Esto significa que cerca de la 
Wiley Ludeña

mitad de la población habita en zonas de baja y mediana densidad, y confirma el hecho de que Lima es una ciudad relativamente "plana". De otro lado, se estima que el $30 \%$ del número total de viviendas del Área Metropolitana está concentrado en áreas predominantes decadentes. Este porcentaje representa 150.000 viviendas. Pero la cifra total de viviendas decadentes asciende al $48 \%$, debido a que las otras áreas registran igualmente "porciones de vivienda decadente".

Respecto a los patrones de asentamiento industrial, el PLANDEMET identifica igualmente cinco tipos de patrones. Estos son: a) industrias distribuidas en el área urbana; b) industrias agrupadas en zonas intermedias; c) industrias nucleadas en bandas periféricas; $d$ ) industrias aisladas fuera de la periferia; y e) parques industriales metropolitanos.

La importancia de la identificación de constantes estructurales del desarrollo urbano de Lima, así como la clasificación de tipos de áreas y la identificación de los patrones de asentamiento residencial e industrial efectuados por el PLANDEMET, tienen la importancia que les otorga su condición de ser un primer gran esfuerzo de revelar las estructuras profundas de Lima en el marco de la realización de un plan de transformación. A diferencia de las propuestas del Plan Regulador de Lima de 1949, los estudios de la ONPU de 1955 o la de Cole de 1957, este planeamiento consigue fundarse en la convergencia de una mayor cantidad de variables que las de las estructuras físico-espaciales.

\section{Miradas cruzadas. Lima desde la barriada y las urbanizaciones}

\subsection{El caso de las barriadas. Criterios y esquemas de clasificación}

Antes de que se constituyera el sustantivo "barriada”, los asentamientos espontáneos surgidos en distintas zonas de Lima recibieron inicialmente el calificativo de "urbanización clandestina". Sin embargo, la vigencia de esta denominación no duró demasiado. Ya en 1953 un documento de la ONPU calificaba de modo determinante a este tipo de asentamientos como "barriadas". En este mismo documento es posible encontrar una primera clasificación de éstas en función de diversos criterios, entre los cuales primaría el del régimen de propiedad de los terrenos invadidos. Las otras variables de clasificación se refieren tanto a la calidad de los materiales empleados, como al grado de desarrollo constructivo y urbano alcanzado en servicios de infraestructura y equipamiento (ONPU, 1953).

Según el tipo de propiedad, el informe clasifica las barriadas en tres tipos: a) en terrenos del Estado; b) sobre terrenos de propiedad particular; y c) sobre terrenos alquilados por lotes. Según el tipo de materiales predominantemente empleados, las barriadas se clasifican en: a) predominio del ladrillo; b) predominio del adobe; c) predominio de la caña; y d) predominio de materiales de desecho. Según el grado de desarrollo y dotación de servicios y equipamiento: a) estable o de un lento desarrollo; b) aumento moderado del número de construcciones; c) desarrollo violento.

Una propuesta clasificatoria que incluye por primera vez criterios de orden morfológico y otros que aluden tanto al nivel de integración o aislamiento de las barriadas, como a la relación de éstas con la ciudad, se encuentra en el informe presentado por Matos Mar (1977) en 1955 a las Naciones Unidas. En este caso, la propuesta puede ser resumida del siguiente modo:

- Ubicación geográfica. Márgenes del río Rímac; falda de los cerros; en la zona urbana; fuera del área urbana.

- Por la configuración urbana. Barriadas de trazo regular en parrilla; barriadas de trazo irregular en parrilla; barriadas adecuadas al relieve del cerro; barriadas con callejón central; barriadas en forma radiada; otros tipos.

Por el grado de aislamiento-integración y relaciones. Barriadas autónomas; complejo de barriadas; barriadas asimiladas a la ciudad.

Un estudio que intentará establecer nuevos criterios de clasificación y formular una suerte de síntesis de todas las variables hasta entonces consideradas -pero en el marco de una propuesta más detalladaes el estudio sobre la situación barrial realizado por el Fondo Nacional de Salud y Bienestar Social entre 1959 y 1960 . Se trata, sin duda, del estudio más detallado sobre la situación de las barriadas que se efectuó hasta entonces. Los principales criterios uti- 
lizados para clasificar las barriadas, aparte de la ubicación por distritos y otros factores socio-económicos, son: las cualidades de formación, el tipo de poblamiento, el régimen de tenencia del suelo ocupado (a nivel de los lotes y barriada), así como el tipo de topografía y el uso precedente del terreno ocupado (FNSBS, 1960).

\section{La clasificación es la siguiente:}

- Formación. Por falta de vivienda; por desalojo; por trabajo.

- Poblamiento. Paulatino; por invasión.

- Tenencia de terrenos referentes a barriadas. Estatal; municipal; propiedad particular; propiedad religiosa; en litigio.

- Tenencia de terrenos a nivel de los lotes. Propietarios; poseedores; invasores; inquilinos.

- $\quad$ Ubicación según la topografía del terreno. Cerros; llano; otros.

- Uso anterior de terrenos. Eriazos; cultivos; basurales; otros.

Otra propuesta de clasificación de los distintos tipos de barriadas desarrollada por un organismo estatal durante la década de los sesenta corresponde a la Junta Nacional de la Vivienda. En este caso, el esquema de tipologización formulado en 1966 se basa en función de criterios de orden morfológico y otros que aluden a la estructuración espacial y funcional del conjunto. Se trata de una clasificación operativa destinada a ponderar la existencia de las barriadas en tanto objetos de transformación proyectual y constructiva (JNV, 1966 y 1967). Los tipos son los siguientes:

- Tipo A. Barriadas con lotes regulares, generosos en área y con terrenos reservados para el equipamiento comunal, las cuales pueden ser rápidamente saneadas.

- Tipo B. Barriadas con comparables rasgos estructurales, sólo que ubicadas en la falda de cerros.

- Tipo C. Barriadas como los tipos A y B, sólo que con una alta densidad poblacional, las cuales son casos de saneamiento que requieren la reubicación de numerosas familias.
Tipo D. Barriadas con una alta densidad poblacional, lotes irregulares y casas de material deleznable, por lo que se requiere un extensivo saneamiento.

- Tipo E. Barriadas como del tipo D, pero con casas construidas de material durable o resistente, por lo que se requiere la realización de un saneamiento a largo plazo.

- $\quad$ Tipo F. Barriadas que deben ser totalmente demolidas.

Si bien no se plantea como objetivo explícito la formulación de una sistemática de tipos característicos, la propuesta de Caminos, Turner y Steffian (1969), en torno a la identificación de las determinantes de diseño en los asentamientos humanos de Lima, resulta un influyente marco de referencias de orden tipológico. La propuesta para el caso de Lima se basa en el estudio de los siguientes casos: Cuevas, El Ermitaño, El Agustino (alto) y El Agustino (bajo) y Mendocita. En este caso los criterios de una clasificación no explicitada como tal son las siguientes: terreno y topografía; tamaño del terreno; composición morfológica (trama circulación vial, trama de circulación peatonal, trama manzanas, trama parcelaria); usos de suelo (privado, público); población; ingresos; servicios urbanos (agua, desagüe, electricidad, teléfono); densidad (poblacional y residencial); y tipos de lotes y viviendas (composición, tamaño, materiales de construcción).

La realización del Plan de Desarrollo Metropolitano de Lima-Callao PLANDEMET va a significar el impulso de una serie de nuevas investigaciones sobre la ciudad de Lima, y específicamente, sobre el problema barrial. En este marco, Carlos Delgado propondría una clasificación que, sin dejar de fundarse en los criterios de clasificación precedentes, significaría una verdadera innovación por la serie de nuevos criterios utilizados. El autor creía entonces que era un imperativo de primer orden la reformulación total de los planteamientos tradicionales de las llamadas barriadas, las cuales debían ser reconocidas no como realidades unívocas, sino como un fenómeno que contiene una multiplicidad de realidades urbanas. Así, él consideraba que se debían sentar las bases de "una descripción clasificatoria que ordene su distribución a lo largo de un eje subdesa- 
rrollo/desarrollo urbano, que reconozca sus características diferenciales, y que abra la posibilidad de orientar políticas concertadas de desarrollo urbano" (Delgado, 1971, p. 130-131). La propuesta de Delgado pretende formularse en oposición a lo que él denomina criterios "generalizantes" como el de Turner, o a la visión formalista de los urbanistas, la cual sólo refleja aspectos parciales y universales del problema, pero no aquellos que le son específicos.

En cierto modo, la propuesta de Delgado intenta conciliar los criterios geográficos, morfológicos y sociales con los intereses de una intervención operativa de transformación en cada barriada. Por otro lado, consciente de las connotaciones negativas, propone reemplazar el término "barriada" por el de "barrio" y reservar su uso sólo para el caso de los asentamientos decadentes del área urbana. Por considerar el grado de desarrollo urbano en base al eje subdesarrollo-desarrollo, la "tipología operacional" propuesta comprende ocho tipos de barriadas: a) barriadas internas de alta densidad; b) barriadas periféricas de alta densidad; c) barrios internos en consolidación incipiente; d) barrios internos en consolidación avanzada; e) barrios periféricos recientes; f) barrios periféricos en consolidación incipiente; g) barrios periféricos en consolidación avanzada, y h) barrios periféricos en medios rurales.

Esta tipología será luego integrada en un esquema general de clasificación, el cual -al integrar otros componentes (como los tugurios en sus diversas manifestaciones)- pretende dar cuenta de aquello que Delgado denomina el "subdesarrollo urbano" en el Área Metropolitana.

Una propuesta clasificatoria que introducirá las variables de tiempo y el número de lotes como factores de clasificación es la formulada por Alfredo Rodríguez y Hélan Jaworski en 1969. Esta hace suya las clasificaciones anteriores, como la que ordena las variables en función de su ubicación en el área urbana (situadas "dentro" del área urbana; situadas "cerca" del área urbana; situadas "lejos" del área urbana). En relación al factor tiempo, la clasificación divide a las barriadas en tres tipos diferenciados:

Barriadas antes de 1950. Constitución de barriadas con un ritmo de aparición y crecimiento poco significativo.
- Barriadas entre 1950-1960. Etapa durante la cual el desarrollo barrial supone un incremento notorio, frente al cual el Estado y otras instituciones se ven obligadas a enfrentar el problema.

- Barriadas después de 1960. Es la etapa en la que las barriadas empiezan a "existir jurídicamente” (Rodríguez y Jaworski, 1969).

Según su tamaño, las barriadas son clasificadas en: a) barriadas grandes, más de 3.735 viviendas, b) barriadas medianas, entre 770 y 3.735 viviendas, $y$ c) barriadas pequeñas, menos de 770 viviendas.

Por otra parte, la propuesta de Rodríguez y Jaworski establece una clasificación de la vivienda barrial según los criterios establecidos por las Naciones Unidas para la evaluación de las condiciones de calidad de la vivienda. Para ello se establecieron los siguientes factores:

- Desarrollo de la vivienda: a) grado de permanencia de la estructura; $y b$ ) intensidad de uso del espacio interno.

- Desarrollo del área: a) grado de consolidación del área (consolidación física del área y consolidación de los servicios); y b) densidad del área: densidad baja o media (menos de 200 personas por hectárea); densidad alta (entre 200 y 400 personas por hectárea); densidad muy alta (más de 400 personas por hectárea).

La investigación barrial posterior a la producción desarrollada durante la década del sesenta no plantearía innovaciones significativas, salvo la consideración de uno u otro factor de menor implicancia. De algún modo, toda la importante serie de investigaciones desarrolladas por el colectivo de investigadores de DESCO, como Abelardo Sánchez León, Gustavo Riofrío, Luis Olivera, Julio Calderón y Mario Zolezzi, entre otros, no hará en parte sino asumir como base los criterios y parámetros ya establecidos hasta entonces -lo que no significa que en algunos casos no se hayan planteado nuevos criterios de análisis o abierto otros campos de interés, como sucede por ejemplo con el tema de la formalidad y la informalidad. 
Uno de los aspectos que luego de la clasificación propuesta por Matos Mar en 1955 no volvió a ser retomado para su eventual depuración, es el que se refiere al problema morfológico o de configuración espacial de las barriadas. Una de las excepciones es la propuesta de Fortunic (1989), quien intentará proponer una nueva clasificación en términos explícitamente morfológicos. La clasificación tipológica propuesta está constituida por cuatro tipos y una serie de subtipos:

- Tipo I. Complejos de asentamientos humanos ubicados en terrenos de alta pendiente. Tipo A: adecuado al relieve del terreno. Tipo B: trazo caótico.

- Tipo II. Complejos de asentamientos humanos ubicados en terrenos de pendiente media y baja. Tipo A: trazo regular en parrilla. Tipo B: trazo irregular en parrilla.

- Tipo III. Asentamientos humanos enclavados en el casco urbano (sólo están ubicados en terrenos de baja pendiente). Tipo A: trazo regular en parrilla. Tipo B: trazo irregular en parrilla. Tipo C: trazo caótico. Tipo D: trazo reordenado.

- $\quad$ Tipo IV. Asentamientos humanos periféricos al casco urbano (en cualquier tipo de terreno y trama urbana variable).

Pese a su esfuerzo por establecer una lectura integral desde el punto de vista morfológico, la propuesta de Fortunic no trasciende el hecho de ser una lectura esencialmente físico-empírica de la ciudad, donde los factores de la trama urbana, adaptación urbana y situación topográfica se convierten en criterios de clasificación de primera jerarquía. En realidad, la propuesta de Fortunic deviene versión ampliada de algunos tipos antes identificados y de variables anteriormente ya aplicadas (ubicación de las barriadas, tipo de configuración, etc.). Si el planeamiento de Fortunic pretendía convertirse en una suerte de lectura "contextualista" del fenómeno barrial, lamentablemente el resultado no llega a lograr este objetivo, ya sea por deficiencias en la aplicación del instrumental teórico del análisis tipológico o por la ausencia de una suficiente base de información empírica.
Una de las contribuciones más importantes al estudio de la historia urbana de Lima, y específicamente al análisis del fenómeno de las barriadas, es las de Eberhard Krob y su libro Die Barriadas von Lima. Stadtentwicklungsprozesse in einer lateinamerikanischen Metropolen (1992). Se trata de un indiscutible aporte que se fundamenta en un exhaustivo y sistemático análisis tanto de las diferentes etapas de la evolución histórica de Lima, cuanto de las características específicas que registra la realidad urbana barrial.

A diferencia de otros estudios en los que el fenómeno de la barriada aparecía como una manifestación desconectada de otras formas de producción de la ciudad, el estudio de Krob integra este hecho en una lectura sincrónica y diacrónica del mismo, pero sin dejar de establecer las relaciones de correspondencia con las lógicas del desarrollo urbano del conjunto de la metrópoli. Aquí el surgimiento, expansión y consolidación de las barriadas con sus distintos tipos aparece como un fenómeno cuyo desarrollo se encuentra estrechamente ligado con los ciclos históricos y tendencias de desarrollo urbano peruano de los últimos 50 años.

Para Krob las principales etapas del desarrollo urbano de Lima definen la existencia de tres grandes etapas: la primera, desde la etapa colonial hasta el inicio del oncenio de Augusto B. Leguía (1535-1919); la segunda, desde el inicio del oncenio hasta el inicio del ochenio de Manuel A. Odría (1919-1948); y la tercera, desde el inicio del ochenio hasta 1985, año límite del período de estudio (Krob, 1992).

Esta periodificación puede resultar obviamente discutible por la omisión de la fase nativa de la existencia de Lima y la no identificación de situaciones diferenciadas durante la extensa primera etapa. Sin embargo, la identificación de las dos últimas etapas resulta pertinente en la medida que explican de modo sistemático las relaciones de correspondencia con el origen y desarrollo del fenómeno barrial.

Los criterios de base empleados para el análisis de las estructuras socio-espaciales se basan en los enfoques de Jürgen Bähr, Gerhard Klückmann y Günter Mertins, principalmente. De ahí que la ciudad -y su conformación específica en cada una de las distintas etapas de su historia- haya sido vista 
Wiley Ludeña

como el espacio de emplazamiento segregado de los estratos altos, medios y bajos, cada uno de los cuales registran modos históricamente diferenciados de ocupación y configuración urbanas. Krob considera imprescindible esta referencia para comprender adecuadamente las razones del lugar, la magnitud y las características tipológicas del fenómeno de las barriadas en Lima.

Respecto al emplazamiento de los estratos altos de la población, se consideran dos espacios diferenciados de localización: uno "tradicional" y el otro actual o moderno. El primero corresponde a sectores de Miraflores y San Isidro (principalmente el área contigua al Golf de San Isidro), delimitados por las avenidas Arequipa, José Pardo y Javier Prado Oeste. El segundo espacio, que empezó a conformarse a partir de la década de los cincuenta, corresponde a la zona de Monterrico y el Lima Polo and Hunt Club, con su respectiva expansión en dirección a La Molina. Si en los casos de Miraflores y San Isidro se trata de una estructura urbanística abierta, compacta y continua con casas-villa o "residencias" controladas por la morfología preexistente, en el segundo caso se trata de urbanizaciones o condominios cerrados con viviendas-chalet en lotes de gran tamaño. Como parte de los espacios de residencia identificados con este sector social, se considera también a algunos balnearios de mar (Krob, 1992).

A partir de la década del setenta, Lima registra la consolidación de las tendencias de crecimiento sectorial-linear respecto a los espacios de residencia para los estratos medios de la población. Las zonas aledañas a la avenida Arequipa (en la dirección Este), al Paseo de la República (en ambos bordes), a la avenida Brasil (en dirección al río Rímac) o a la avenida Colonial (en ambos bordes) darían lugar a los nuevos espacios para la clase media limeña. Santa Catalina, San Luis, Santiago de Surco, San Borja, Maranga, entre otras, son las urbanizaciones características de este sector social. En este caso sus distintos niveles (alto, medio-medio y bajo) se definen en función de la cercanía o lejanía de los espacios destinados a los estratos altos o bajos, respectivamente. El promedio del área de lote en este sector oscila entre los 100 a $160 \mathrm{~m}^{2}$. La vivienda es el típico "chalet limeño" reinterpretado con dimensiones reducidas, mientras que la urbanización se inserta como hecho continuo a la trama urbana preexistente.
A diferencia de cierta homogeneidad tipológica en el caso de las áreas de residencia de los estratos altos y medios, Krob registra 4 tipos de espacios de residencia para los estratos bajos de la población: a) tugurios (zonas totales o parciales del Rímac, Barrios Altos, Monserrate, entre otras), b) barrios pertenecientes a las asociaciones, mutuales o cooperativas de vivienda (barrios de "núcleos básicos" y construcción progresiva, con problemas de servicios urbanos); c) las Urbanizaciones Populares de Interés Social UPIS (tipo de urbanización nueva o una forma de barriada replanteada establecida por norma); y d) las barriadas (casos tradicionales: Leticia, San Cosme, Independencia, entre otras).

Existe una visión más o menos asumida sobre la barriada, que en este caso el autor consigue rebatir al analizar las distintas posibilidades derivadas de la estructura poblacional de las mismas. Queda claro en relación a este aspecto que la barriada no es una realidad social y económicamente homogénea. Para una mejor identificación de cada caso, Krob propone un análisis "microgeográfico" de la estructura poblacional de cada barriada, en función de las variables pertinentes.

\subsection{Urbanizaciones, tipologías y la expansión no barrial}

El reconocimiento de la existencia de formas de producción urbana y lógicas de ocupación del suelo había quedado no sólo registrado en documentos como el PLANDEMET, sino que luego se haría premisa básica de análisis de la ciudad. En este marco, la demanda de sistematizar en grandes tendencias estos modos diferentes de construir ciudad sería el objetivo de numerosas aproximaciones, entre ellas la serie de estudios como el de Abelardo Sánchez León, Raúl Guerrero, Julio Calderón y Luis Olivera. El planeamiento de la existencia de dos modalidades de crecimiento de Lima, registrado en Tugurización en Lima Metropolitana (1979), es un caso concreto.

Para los investigadores de DESCO, el crecimiento de Lima Metropolitana registra dos modalidades básicas de crecimiento o expansión: la "expansión barrial” y la llamada "expansión no barrial”. La primera tiene que ver con la expansión de los asentamientos barriales, la cual empieza a hacerse cada vez más predominante desde la década del cuarenta, tanto en su modalidad de "barriada externa" 
como de "barriada interna". En cambio, la segunda alude a todas las formas de expansión, generadas a partir de las llamadas urbanizaciones: desde aquellas pertenecientes a la clase alta hasta las que son edificadas por aquellos sectores populares organizados en cooperativas o asociaciones de vivienda.

La expansión no barrial es, ciertamente, una definición por negación de la modalidad barrial de expansión, por lo que puede parecer una generalización que alude a todo lo que no sea una forma de expansión barrial. Sin embargo, existen algunas precisiones: los autores establecen una distinción entre las "urbanizaciones populares" y las "urbanizaciones de los sectores medios", no sólo por la composición social de sus habitantes, sino también por la cercanía o distancia de estas respecto a los asentamientos barriales.

La urbanización popular es definida como un tipo de asentamiento destinado a un sector popular de escasos ingresos. Se trata por lo general de urbanizaciones creadas por asociaciones o cooperativas de vivienda. Se encuentran ubicadas al interior de los distritos, donde existe una mayoritaria población barrial. Son urbanizaciones que, aparte de contar con la infraestructura básica de servicios, comprende normalmente la construcción simultánea de viviendas. En este caso, todas las etapas de gestación y posterior desarrollo de la urbanización se producen de manera independiente y en función de la capacidad económica e iniciativa de la asociación o cooperativa comprometida en el proyecto.

Los autores de Tugurización en Lima Metropolitana sostienen que, respecto a los "pueblos jóvenes", las urbanizaciones populares carecen de una serie de ventajas de las que disfrutan éstos, como son estar exonerados del pago del impuesto predial, así como las tarifas especiales por los servicios de agua y luz eléctrica.

La urbanización de clase media se presenta como un fenómeno distinto. Por lo general, su gestación se encuentra en manos de una empresa urbanizadora y no de una organización de propietarios. Por otra parte, los lotes son objeto de compra individual y no colectiva, como sucede en el caso anterior. Aquí los trabajos de urbanización (pistas, agua, desagüe, electricidad) preceden a la entrega de los lotes y a la construcción individual de las viviendas. Estas, además, se realizan en función de las preferencias y capacidad de cada familia.

Entre el tipo de urbanización popular y el de urbanización de clase media se produce una serie de modalidades intermedias, entre las cuales es posible advertir distintos rasgos. Existen urbanizaciones populares donde las viviendas son edificadas a posteriori de forma individual. También existen casos en muchas urbanizaciones de clase media donde es posible encontrar programas de vivienda en serie, construidas en el marco de algún programa de vivienda emprendido por mutuales y otros organismos financieros. Asimismo, es posible registrar formas de organización cooperativa.

El tercer tipo de urbanización, constituidas por la "expansión no barrial", corresponde a los sectores de altos ingresos. Se trata de una expansión residencial de carácter eminentemente suburbana (Sánchez et al., 1979). Las zonas preferidas para este tipo de expansión son el Sur y el Este, tal como ocurre con Córpac en San Isidro; San Borja en Surco y La Molina. El objetivo principal de estas urbanizaciones es ubicarse lo más lejos posible de los asentamientos barriales de Lima.

A diferencia del "crecimiento por suburbios", que caracteriza a la implantación residencial de los sectores de altos ingresos en otras metrópolis desarrolladas, los autores señalan que en Lima la implantación de estos es insignificante demográficamente, aun cuando existan habilitaciones de áreas muy extensas como el caso de La Molina. La zona de urbanizaciones de este tipo constituyen casi una "tripa angosta" en dirección Este de la ciudad.

Para los autores, las modalidades de expansión barrial y no barrial sólo parecerían aplicarse a fenómenos que se originan a partir de una ciudad ya consolidada, es decir, la ciudad anterior a la década de los cuarenta o cincuenta. Por lo tanto, no sirven para explicar fenómenos de crecimiento anteriores a esta situación. En este sentido, la modalidad "de expansión por relleno", prioritaria en la ciudad antes de la década del cuarenta, no consigue explicar la serie de fenómenos urbanos sucedidos en Lima antes de esta época. El caso de La Victoria, una suerte de primera "ciudad tizada" del siglo XX, resulta reve- 
Wiley Ludeña

lador: puede estar tan lejos de la urbanización Santa Beatriz como tan cerca de Villa El Salvador.

La clasificación propuesta presenta, por ello, una serie de imprecisiones en la definición de aquello que le es propio y específico respecto a otra modalidad. Porque no se trata sólo de descubrir en las modalidades de ocupación del suelo la razón de base para establecer las diferencias o semejanzas, sino en los modos de producción, consumo y distribución del espacio urbano.

Una mayor precisión en la definición de aquello que tiene que ver con la llamada modalidad de expansión no barrial se dará en otra investigación posterior: El laberinto de la ciudad (1980). Aquí, la definición del proceso denominado "urbanización convencional" no sólo resulta mejor caracterizada, sino que permite una mayor comprensión de la lógica que gobierna gran parte del sistema de producción urbanística de la ciudad. Se trata de una definición que resulta tal no por su negación de otra realidad, sino por el sentido afirmativo de una realidad existente.

La principal característica del proceso de urbanización convencional es que su desarrollo está en función de la iniciativa y el capital privados. Aquí el dominio de lo privado comprende al propietario del terreno, a la empresa urbanizadora o a la entidad financiera. En unos casos, estas funciones se cumplen a través de una misma empresa o familia, y en otros, se reparten el proceso entre varias empresas (Sánchez y Calderón, 1980). En suma, el proceso de urbanización incluye los siguientes agentes: el propietario del terreno, el urbanizador, la empresa constructora y el vendedor/comprador. El Estado participa (por medio de los organismos pertinentes) como un mero ente regulador y fiscalizador.

Dentro de este proceso de urbanización convencional se distinguen dos modalidades en función del sujeto que emprende el proceso de urbanización. Una de ellas tiene que ver con la existencia de un agente o empresario urbanizador, quien se encarga de crear la urbanización desde la compra de un terreno hasta la venta de los lotes. La segunda modalidad se relaciona con el tipo de urbanizaciones donde el principal gestor es el mismo propietario del terreno (Sánchez y Calderón, 1980). Esta se- gunda modalidad es la que más urbanizaciones cuenta en su haber.

En comparación con la investigación barrial, la identificación de los patrones de crecimiento de Lima en relación a la urbanización no ha sido precisamente una preocupación permanente. Uno de los planteamientos que trataría de integrar esta problemática en un enfoque global del desarrollo de Lima es el estudio de Jean Paul Deler, Lima 1940-1970. Aspectos del crecimiento de la capital peruana (1975).

En el marco de lo que el autor señala como el proceso de conquista del espacio limeño, se identifican dos modalidades esencialmente distintas en relación a la "colonización del espacio". Por un lado, la inscrita en lo que podría denominarse un proceso de urbanización clásica, hecha dentro del marco legal de las instituciones de urbanismo y con la participación de promotores privados, cuya economía es de libre competencia. Se trata de una modalidad que opera con las mismas características que las que se conocen en las ciudades capitalistas desarrolladas. La otra se opone radicalmente a la primera. Se trata del fenómeno de "urbanización espontánea y de autoconstrucción".

Siguiendo con los parámetros del análisis ecológico urbano, Deler propondrá un esquema de diferenciación de "tipos de barrios", recogiendo así la propuesta del PLANDEMET respecto a las cuatro áreas de expansión que le otorgan la fisonomía a Lima (las áreas nucleares; el anillo extranuclear; las áreas periféricas al casco urbano; y las áreas corredor de los asentamientos nucleares).

Deler consigue identificar cuatro tipos de barrios, los cuales se constituyen a modo de "paisajes urbanos". Estos son:

El "cuadrilátero primitivo". Se trata del damero fundacional de Lima, el área central. Es la city constituida por una trama continua y concentradora del poder político y económico.

- Primer anillo de expansión. Está constituido por el ensanche producido en torno al área central (Rímac, La Victoria, Breña, Barrios Altos). Es un anillo casi continuo de barrios con fuerte densidad poblacional y constructi- 
va. En términos de tejido urbano resulta saturado, heterogéneo y degradado. La densidad promedio es superior a los $130 \mathrm{hab} / \mathrm{ha}$. Se registran funciones múltiples.

- Segundo anillo de expansión. Se trata de una zona que se extiende más allá del primer anillo en dirección al Sur y la parte Oeste de la ciudad. Representa al tejido urbano mixto, pero globalmente más despejado. Se compone de barrios que oscilan desde aquellos pertenecientes a la clase media (Lince y Pueblo Libre, entre otros), hasta aquellos que sirven de residencia a las clases altas (San Isidro, Miraflores o la zona de Chacarilla). En el primer caso, se trata de barrios con densidades entre 0 y 130 hab/ha. En el segundo, las densidades son de $30 \mathrm{hab} / \mathrm{ha}$.

- Las "barriadas". Constituyen el cuarto tipo de barrio. En este domina ampliamente la función residencial. La casa individual es patrón exclusivo del asentamiento. Estos barrios poseen una densidad -al menos en las barriadas anteriores a 1960- inferior a los 80 hab/ha., y hay algunas que tienen una densidad de 30 hab/ha. Se encuentran por lo general sub-equipadas y carecen de servicios de infraestructura (Sánchez León y Calderón, 1980).

A diferencia de propuestas precedentes, el planteamiento de Deler intenta esbozar una clasificación a partir de la integración de una serie de aspectos hasta entonces asumidos de modo aislado. Tal es el caso de la relación establecida entre vivienda y morfología urbana y entre destinatario social y localización residencial, entre otros. Puede observarse tal vez la ausencia de una lectura más precisa y detallada de algunos procesos, por lo que su planteamiento puede pecar por ofrecer generalizaciones no justificadas. Sin embargo, se trata de un planteamiento que intenta ser integral e integrador en su diagnóstico. Puede considerarse además como uno de los primeros esfuerzos de interpretación del desarrollo urbano de Lima a partir de la definición del "barrio" como unidad de constitución espacial.

Los profundos cambios que ha empezado a experimentar Lima tras la puesta neoliberal y neopopulista de la década de los noventa, ha su- puesto el inicio de modificaciones significativas en su estructura urbana y morfológica. En este contexto, fenómenos como el de la globalización neoliberal, el programa urbanístico posmoderno, la creciente privatización y fragmentación excluyente del espacio urbano, han generado un nuevo ciclo de expansión urbana dominada por la lógica de la segregación socio-espacial y la preeminencia de formas urbanísticas de control y selección social.

Este fenómeno de cambios en la estructura urbana de la metrópoli limeña no ha sido aún objeto de formulaciones teóricas integrales ni registros de orden histórico sistemáticos que pudieran traducirse en criterios y esquemas de tipologización pertinentes. Sin embargo, junto a aportes de inicio como los de Chion (1999), Fernández (2001) y Ludeña (2002), los estudios del colectivo dirigido por Jürgen Bähr en torno al registro sistemático de los cambios acontecidos recientemente en la estructura urbana de ciudades como Lima y Santiago de Chile, son una primera e importante contribución.

En relación a la nueva estructura socio-espacial y morfológica de los barrios residenciales (fundamentalmente de carácter privado), los autores proponen una tipologización basada en los grados de encerramiento y relación con la ciudad (MeyerKriesten, Plöger y Bähr, 2004). Los tipos considerados son los siguientes:

Tipo 1. Condominios exclusivos de la clase alta; ubicación en el territorio suburbano consolidado; antiguos terrenos de agricultura; residencias individuales en grandes parcelas; intensa relación con el paisaje y el tiempo libre; extremas medidas de seguridad.

- Tipo 2. Condominios periurbanos en la periferia creciente, clase social alta; vivienda estandarizada en lotización en serie; fuerte integración al paisaje y al uso del tiempo libre; alta seguridad.

- Tipo 3. Condominios de la clase media; ubicación suburbana; construcción estandarizada; equipamiento, seguridad e instalaciones comunales varían según clase social.

- Tipo 4. Condominios con respaldo o subsidio estatal; clase media baja hasta clase baja 
Wiley Ludeña

alta; construcción simple estandarizada, a veces de varios pisos; leves medidas de seguridad.

- Tipo 5. Vecindades posteriormente cercadas, diferentes clases sociales; cercado de calles frecuentemente sin autorización legal; informalidad de las medidas.

- Tipo 6. Condominios de edificios; edificios altos en áreas de vivienda densificadas y céntricas de la clase media y alta; instalaciones comunitarias extensas y medidas de seguridad altas.

- $\quad$ Tipo 7. Megaproyectos; ubicación periurbana; diferentes clases sociales y tipos de construcción; normas de uso de suelo cambiadas; infraestructuras de servicios propias (comercio, educación, etc.) brindan el carácter de una pequeña ciudad.

- Tipo 8. Condominios de fines de semana o vacaciones; lejos del área metropolitana, instalaciones de recreo al aire libre.

Esta tipología formulada como una síntesis conjunta para los casos de Santiago de Chile y Lima registra casos aun no existentes o insuficientemente desarrollados en la capital peruana. Sin embargo, resulta previsible pensar que alguno de estos tipos que ya empiezan a prefigurar su presencia en la capital peruana- no tardarán en hacer su aparición y posterior consolidación, tal como viene aconteciendo como por ejemplo con los tipos 1 y 2 . Seguramente cuando el estudio para el caso de Lima sea concluido en sus resultados finales, algunas de estas tendencias y tipos serán objetos de replanteamiento o validación teórico práctica.

\section{Ciudad y estructura. La búsqueda de un modelo}

\subsection{Tendencias, tipologización y segregación socio- espacial de Lima}

Si bien los estudios del PLANDEMET representan una primera puesta de principios teóricometodológicos basados en la ecología urbana sistematizada por la Escuela de Chicago de Park y Burguess, una versión más compleja y depurada de esta perspectiva se desarrollaría desde mediados de la década del setenta como resultado del interés de la investigación urbana alemana por construir modelos teóricos para la ciudad latinoamericana (Bähr y Mertins, 1981; Bähr y Klückmann, 1985; Krob, 1992; Bähr y Mertins, 1995a y 1995b).

Entre los planteamientos iniciales esbozados para el caso de Lima bajo esta perspectiva de investigación puede mencionarse el de Bähr y Klückmann. Se trata de una propuesta sustentada en las premisas y la identificación de las lógicas de la segregación socio-espacial y funcional en la ciudad. El principal aporte es la formulación de un modelo que refleje la estructura socio-espacial de Lima a partir del análisis de un extenso dominio empírico de referencia.

En este caso, la caracterización de la estructura socio-espacial de Lima se basa en la interpretación de los datos y tendencias registradas por el censo de 1981 y la identificación de 794 zonas censales. Las principales variables de análisis, de las 30 establecidas, son las de pertenencia a un estrato social, el ingreso familiar, la magnitud y estructura familiar, entre otras. De este análisis se establecen 7 grupos a partir de la existencia básica de tres sectores con estatus socio-económicos distintos: los sectores alto, medio y bajo (Bähr y Klückmann, 1985). Los grupos son los siguientes:

Sector de status socio-económico alto. Grupo familiar muy pequeño. Población de mayor edad. San Isidro, Miraflores, zonas de la avenida Salaverry, parte de la Punta. Villas y edificios de apartamentos.

- Sector de status socio-económico alto. Grupo familiar grande. Población joven. Monterrico en dirección a La Molina, partes de Surco, la Encantada, Chorrillos. Chalets y edificios de apartamentos.

Sector de status socio-económico medio. Grupo familiar medianamente grande. Población de mayor edad. Magdalena, Pueblo Libre, La Perla, Lince. "Chalet" en serie, bloques de departamentos.

- Sector de status socio-económico medio. Grupo familiar grande. Población joven. San Miguel, parte de Surco, partes de La Molina, 
partes de Lima norte y Lima sur). "Chalet" en serie, bloques de departamentos.

- Sector de status socio-económico mediano bajo. Grupo familiar muy pequeño. Población de edad (una gran porción de Tugurios y viejas barriadas). Centro de Lima, Rímac, Breña, La Victoria, Surquillo, parte del Callao, parte de Barranco, parte de Chorrillos, San Martín de Porras, Comas, San Juan de Miraflores. Casas a pie de vereda, quintas, casas de vecindad, "villas", conventillos, casa inconclusa de barriada.

- Sector de status socio-económico bajo. Grupo familiar grande. Joven economía. Población activa (barriadas viejas y tugurios). Independencia, Comas, Canto Grande, Villa El Salvador, Pamplona. Casas de vecindad, conventillos, callejones, corralones, casa inconclusa de barriada.

- Sector de status socio-económico bajo. Grupo familiar grande. Población muy joven (barriadas recientes). Casa inconclusa de barriada.

La formulación de este esquema de estructuración socio-espacial terminaría siendo validada en su fundamentación por un análisis histórico de aquellos factores de determinación y condicionamiento que participaron (y lo hacen aún) en la constitución histórico-social de la metrópoli limeña. Aquí la lectura sincrónica y diacrónica del proceso urbano y sus respectivos momentos deviene basamento de una verificable visión sistémica de la realidad urbana (Bähr y Mertins, 1995a y 1995b).

Si bien el dominio del análisis alude al conjunto de la realidad urbana latinoamericana, la propuesta de periodificación y caracterización tipológica de cada momento histórico formulada por Bähr y Borsdorf puede hacerse extensiva al caso limeño, desde luego con las atingencias del caso. Los autores establecen la existencia de 4 modos distintos de estructuración y funcionamiento, o en otras palabras, cuatro momentos tipológicos diferenciados. Estos son: a) la ciudad colonial compacta; b) la ciudad sectorial (18201950); c) la ciudad polarizada (1950-1990), y d) la ciudad fragmentada, desde 1990 (Bähr y Borsdorf, 2005).
La ciudad colonial compacta se define en su organización como una estructura social circular de los barrios definidos en su estatus y función en base a la proximidad al epicentro del poder y la vida urbana colonial: la plaza principal. La ciudad sectorial republicana, entretanto, basa su funcionamiento en la diferenciación sectorial orientada a estructuras lineales. Ello significa un proceso combinado de gradual abandono del centro colonial para el establecimiento sectorizado tanto de los estratos altos de la población como de la naciente industria local en dos zonas lineales: los bulevares de inspiración haussmanniana y las avenidas industriales, respectivamente. El desarrollo sectorial significa una ruptura radical con la estructura compacta y circular de la ciudad colonial.

La tercera etapa, de la ciudad polarizada, se caracteriza por un modo predominante de expansión celular en reemplazo de la organización sectorial del espacio urbano. Ello, en el contexto del creciente proceso de suburbanización registrado a partir de la década de los años cincuenta, vía la expansión de la periferia barrial y la ampliación de los barrios de los estratos altos y medios.

La ciudad fragmentada, aquella que empieza a gestarse desde 1990, registra una nueva forma de separación de funciones y elementos socio-espaciales sobre la base de una nueva ampliación de la tendencia sectorial-lineal y el crecimiento celular fragmentado. Esta es la ciudad de la implantación de unidades económicas y residenciales de manera dispersa y mezclada, bajo criterios de autosuficiencia y exclusión deliberada. En este caso se observa una creciente privatización del espacio urbano, así como el agravamiento de las condiciones de vida de los sectores más pobres de la ciudad.

Sobre la base de investigaciones relacionadas tanto al análisis de las estructuras de ocupación socioespaciales como a las tendencias históricas del proceso urbano, Bähr y Mertins construyen un "modelo empírico" de estructuración de la ciudad latinoamericana, el cual -con las observaciones respectivaspuede hacerse igualmente extensivo al caso de Lima. Se trata de un destacado aporte teórico.

El modelo, formulado en 1981, se constituye de una estructura de 4 zonas concéntricas, atravesadas sectorialmente por ejes-zonas radiales en la direc- 
Wiley Ludeña

ción centro-periferia. En el espacio de referencia el esquema registra componentes nucleares ubicados de manera dispersa y mezclada con una ocupación preeminente en el área periférica (Bähr y Mertins, 1995a y 1995b).

El esquema aplicado a Lima con referencia a las zonas concéntricas no continuas, podría tener la siguiente estructura:

- $\quad$ La City (el centro histórico).

- Zona mixta o de transición (área central con parte del Rímac, parte de Monserrate y el primer ensanchamiento republicano a través de las urbanizaciones como La Chacrita, la Unión, La Exposición y parte de La Victoria).

- Barrios marginales del interior (tres modalidades: antiguos barrios de los estratos altos y medios degradados; antiguos barrios de los estratos bajos y antiguas barriadas legales y semilegales). Barrios Altos, Monserrate, parte del Rímac y la barriada Leticia y otras en torno al área central.

- Barrios de los estratos bajos y medios bajos. La Victoria, Breña, parte del Rímac, parte de Lince.

Las tres primeras zonas corresponderían al área central de la ciudad. La cuarta es aquella zona identificada con aquellos sectores lineales que tras romper la estructura circular de la ciudad colonial, se expanden radialmente como una especie de "cuñas" desde el centro a la periferia. Estos son las siguientes:

- Barrios residenciales de los estratos bajos y medios bajos. La expansión en varias direcciones: área central-La Victoria-San Luis-Ate, área central-Breña-San Martín de Porres.

- Barrios residenciales de los estratos medios y medios altos. Expansión en dirección sur: Paseo Colón-Jesús María-San Miguel-Magdalena.

- Barrios residenciales de los estratos altos. Expansión en dirección sur: Paseo Colón-Jesús María-San Isidro-Miraflores

Todas estas zonas se ven "salpicadas" indistintamente de componentes nucleares, que a modo de subcentros o barrios residenciales (pequeños, medianos y grandes), pertenecientes a los sectores bajos, medios y altos, se han emplazado siguiendo la orientación de las lógicas de segregación socio-espacial de la ciudad. Ahí están, para el caso de Lima, barrios como La Molina, Cieneguilla o Los Olivos, entre otros.

Los autores han considerado este modelo como uno de carácter dinámico que no se ajusta directamente a un caso específico de ciudad. En él, cada ciudad puede encontrar algunas $-y$ no necesariamente todas- las referencias estructurales básicas de su propia configuración, tal como ocurren en este caso con Lima.

\subsection{Contextualismo y ciudad. Edilicia especialy de base}

En la línea de la lectura espacial esbozada por Deler, la propuesta "contextualista" de Aldo Mantovani tratará de llevar a un plano de mayor precisión aquellos rasgos morfológicos característicos del desarrollo de Lima. En realidad, se trata de la primera interpretación morfológica de Lima desarrollada a partir del instrumental teórico y metodológico de la investigación tipológica correspondiente a la llamada "escuela italiana" (Saverio Muratori, Gianfranco Caniggia y Carlo Aymonino, entre otros).

Para Mantovani, "la estructura de la metrópoli es el resultado construido de un proceso unitario articulado en sucesivas agregaciones de unidades morfológicas" (Mantovani, 1980, p. 19). De ahí que su planteamiento se base en la descomposición del escenario limeño en cuatro niveles de análisis: a) el proceso de crecimiento; $b$ ) la forma del crecimiento; c) las unidades residenciales; y d) la estructura espacial.

Tras la descomposición contextualista del espacio urbano limeño, Mantovani recompone la serie de "piezas", para proponer como síntesis nueve "sistemas de contextos" como los constitutivos de la realidad contextual limeña. Estos son:

- Sistema A. La ciudad amurallada.

- Sistema B. Perteneciente a los "pueblos".

- $\quad$ Sistema C. Primera etapa del ensanche. 
- $\quad$ Sistema D. Segunda etapa del ensanche.

- $\quad$ Sistema E. Ensanche de los balnearios.

- Sistema F. La "urbanización paisajista”.

- Sistema G. La “urbanización paisajista tardía”.

- Sistema H. La "urbanización funcional”.

- $\quad$ Sistema I. La barriada.

La propuesta de Mantovani intenta no sólo completar algunos vacíos en la precedente lectura morfológica de Lima, sino avanzar en la identificación de algunas características no señaladas anteriormente. Pueden observarse como limitaciones el hecho de que algunas generalizaciones se sustentan en una insuficiente investigación empírica, o que algunos de los sistemas de contextos delimitados requieran de una mejor precisión en términos de contenido. En todo caso, la investigación de Mantovani puede considerarse como una de las primeras que inauguran de modo explícito una tradición de investigación tipológica del espacio urbano limeño basado en la identificación de las edilicias especiales y de base.

\subsection{Ciudad, barrios y estructura urbanistica}

Todo barrio es un componente de mediación y estructuración entre la dimensión de los objetos construidos y la dimensión urbana en lo que concierne a la delimitación de áreas, zonas o distritos. Es su unidad básica de estructuración socio-espacial de la ciudad, por lo que reproduce en su escala su misma complejidad.

No obstante que la tipologización de los barrios en el marco de una comprensión integral de las lógicas de estructuración urbana resulta uno de los principales objetos de estudio, algo que aún no había merecido un registro sistemático de la realidad, alude a la caracterización de los barrios en función de la estructura morfológica de la ciudad conectada con las distintas tradiciones del urbanismo peruano. Esta es la propuesta de Ludeña (2004). En este caso la propuesta se basa en el registro completo de los barrios residenciales producidos en Lima durante el período mencionado. Se registraron en total 1186 unidades urbanísticas.
Los barrios pueden ser clasificados de distinta manera según la antigüedad, la función, el status social, la ubicación geográfica, la procedencia de la población, entre otras variables. En esta oportunidad la clasificación de base propuesta se fundamenta en la convergencia de dos criterios esenciales: el del promotor o gestor del barrio y la forma específica de producción del mismo. De esta operación se distinguen las tres tradiciones del urbanismo peruano (Ludeña, 2004): a) barrios - urbanismo estatal (unidades vecinales, conjuntos habitacionales, urbanizaciones populares de interés social, entre otros), b) barrios - urbanismo privado (urbanizaciones, condominios residenciales, entre otros); y c) barrios urbanismo barrial (barriadas, "pueblos jóvenes", asentamientos humanos, entre otros).

Posiblemente el dato físico en sí mismo no sea un elemento que permita una clara distinción entre las distintas versiones de barrio: después de todo, hoy en Lima puede ser difícil advertir las diferencias entre una pujante barriada y una urbanización de clase media deteriorada, como entre un conjunto habitacional estatal y alguna de las nuevas agrupaciones privadas de vivienda. Si existen elementos de diferenciación, éstos se dan en el carácter mismo de los procesos de producción, intercambio y consumo.

Existen otras formas de clasificación cuyo objetivo es el de caracterizar la estructura morfológica interna del barrio, así como la orientación programática del mismo desde el punto de vista de los métodos de proyectación urbanística. Los criterios propuestos para la clasificación de los tipos de habilitación son los siguientes (Ludeña, 2004):

- Por la fase de inicio de la habilitación. Habilitación ex novo; habilitación por renovación.

- Según el tamaño de la habilitación. En el caso limeño el tamaño promedio de los barrios resulta-en comparación del promedio internacional- pequeño, acorde con la escala reducida de la inversión inmobiliaria. Aquí, el rango principal de fluctuación de los barrios según el número de habitantes oscila apenas entre $250 \mathrm{y}$ 2.000 habitantes, es decir, entre 50 y 400 viviendas. Entre los barrios de más de 50 lotes o viviendas hasta más de 5.000 unidades de lotes o viviendas, se han establecido 7 categorías: 
Wiley Ludeña

barrio tipo A (más de 5.000 lotes/viv.); barrio tipo B (2.500 -5.000 lotes/viv.); barrio tipo C (1.000-2.500 lotes/viv.), barrio tipo D (5001.000 lotes/viv.); barrio tipo E (100-500 lotes/viv.); barrio tipo F (50-100 lotes/viv.); y barrio tipo $\mathrm{G}$ (menos de 50 lotes/viv.).

- Por el grado de habilitación u ocupación del lote. Lotización urbanizada, lotización tizada; lotización con núcleos básicos; lotización con servicios; habilitación con vivienda simultánea.

- Por la configuración morfológica. Las variables son las siguientes: a) sistema vial; b) espacios públicos; c) barrios según su ubicación, formato y relación con el contexto preexistente; d) retícula urbanística; e) orden formal; f) manzana predominante; g) escala de integración vecinal; h) trama parcelaria de la manzana; e i) teoría o modelo urbanístico.

- Por las teorías y modelos urbanísticos de base. Se registran los siguientes casos: a) barrio neobarroco; b) barrio jardín; c) barrio pragmático; d) barrio moderno; e) barrio manzana-bloque-lote; f) barrio manzana; g) barrio espontáneo; h) barrio sectorizado.

En relación a una clasificación de los barrios según la teoría o modelo urbanístico reproducido, el estudio realizado señala que el perfil urbanístico de la metrópoli limeña está determinado en gran medida por el formato del llamado barrio pragmático en un $40,5 \%$. Le sigue en importancia el barrio sectorizado en un $21,5 \%$. Con un 13,2\% aparecen los barrios espontáneos, característicos de la versión más radicalmente libre de barriadas. Barrios como Santa Beatriz o Santa Cruz, expresiones acabadas de los barrios neobarrocos, constituyen apenas el 1,4\%. Y conjuntos habitacionales como la Unidad Vecinal No 3 o la Residencial San Felipe, entre otros, en tanto formas de barrio moderno alcanzan un 5\% del total (Ludeña, 2004).

Ya sea en relación a su pertenencia a alguna de las tres tradiciones urbanísticas (estatal, privada o barrial), o bien en referencia a su clasificación según la serie de variables de orden funcional o morfológico, la tipologización propuesta no se basa en la elección de casos identificados en estado puro. Aquí la identificación del barrio y sus componentes con uno u otro parámetro se sustenta en el criterio de predominancia de ciertos aspectos sobre otros. Por tanto, el esquema no aspira a registrar hechos absolutos, sino tendencias o preeminencias relativas, mucho más si se reconoce que el urbanismo limeño es en esencia un conglomerado de mezclas y procesos sorprendentes de hibridación tipológica.

\section{A modo de conclusiones}

Uno de los primeros rasgos sujetos de observación respecto al conjunto de planteamientos formulados en torno a una tipologización de los componentes y procesos del desarrollo urbano de Lima, alude a una serie de propuestas inconexas entre sí, de desarrollo fragmentado y sin líneas continuas de investigación. Se trata de planteamientos que en la mayoría de los casos se agotan o concluyen en sí mismos, sin capacidad de generar una tradición permanente y consistente de estudios.

Respecto a las relaciones entre la fundamentación empírica de las propuestas y los propósitos de orden teórico, se debe establecer una diferencia entre todas aquellas propuestas formuladas antes y después de los planteamientos de Cole y el PLANDEMET de mediados de los sesenta. Todo el conjunto de planteamientos anteriores se sustenta básicamente en clasificaciones empírico-nominales de un apreciable acento descriptivo, y sin ninguna aspiración de construir modelos teóricos. En cambio, la casi totalidad de las propuestas formuladas posteriormente no sólo se sustentan en formulaciones teórico-metodológicas asumidas de manera consciente, sino que éstas en muchos casos se dirigen a recrear contenidos teóricos sobre la base de un amplio y variado registro empírico.

La preeminencia de propuestas formuladas desde la ciencia geográfica es otro de los rasgos a registrar. Podría afirmarse que las principales contribuciones al estudio urbano de Lima provienen desde los dominios de esta disciplina: Cole, Bähr, Deler Krob, entre otros, son geógrafos de profesión. La visión sociológica puede considerarse como un segundo enfoque de importancia: ahí se encuentran los aportes de sociólogos como Quijano, Riofrío, Meneses, Sánchez León, entre otros. Entre los antropólogos con aspiraciones de formular propuestas de sistematización tipológica del fenómeno urbano, Matos Mar resulta un destacado exponente 
con su ya casi mítico estudio de 1955 sobre las barriadas de Lima. Contribuciones como las de Córdova, Correa y Mantovani, entre otros, acotan una perspectiva específica y relativamente dispersa desde los dominios del urbanismo y la arquitectura.

Visto en conjunto, se observa entre las propuestas por lo menos dos modos distintos de emplear el "material histórico". En un caso se encuentran planteamientos como los de Cole, Deler, Krob o Bähr, para quienes la construcción de un modelo que refleje las circunstancias del presente se basa en un análisis sistemático del proceso histórico registrado por la ciudad. Aquí la historia deviene instrumento esencial para revelar la dimensión actual de los fenómenos, mientras que los análisis sincrónico y diacrónico se articulan como un solo discurso. De otra parte, existen planteamientos en los que no es posible advertir este hecho, toda vez que como sucede en algunos casos no deviene objetivo deliberado. Propuestas como las de Córdova, Matos Mar, Del- gado o Fortunic registran el sentido de lecturas basadas estrictamente en un análisis de los hechos del presente, donde la aproximación histórica puede aparecer-si es que se produce- como un hecho incidental.

El conjunto de planteamientos registrados en el presente texto constituyen en su heterogeneidad, distintos niveles de profundidad y grados de sistematicidad. Representan de alguna manera una especie de capítulo inicial de una propuesta teórica que requiere aún definir con precisión sus propias fronteras. En todo caso, se trata de un conjunto en plena construcción, el cual requiere adoptar coherencia epistemológica y articulación teórica para otorgar sentido a todas aquellas dimensiones y facetas de la realidad urbana todavía incompletas en su registro y descripción. La complejidad y violenta dinamicidad manifiesta del proceso y tejido urbanos de Lima no ha conseguido aún ser reflejada en un modelo teórico integral e integrador.

Figuras 1a y 1b. Plan Piloto de Lima (1949). (a) Plano de zonificación de usos de suelo; (b) esquema de dinámica urbana.

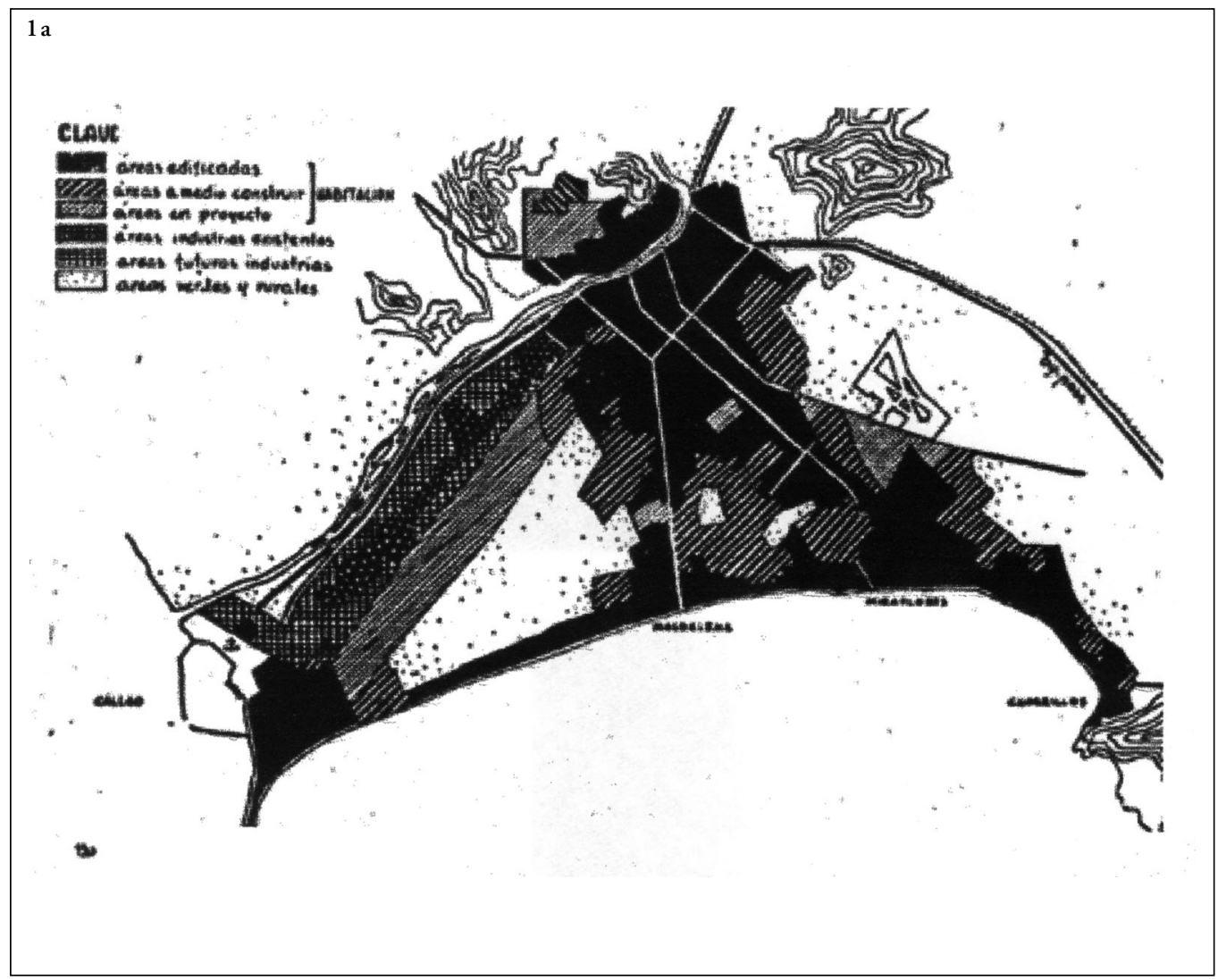


Wiley Ludeña

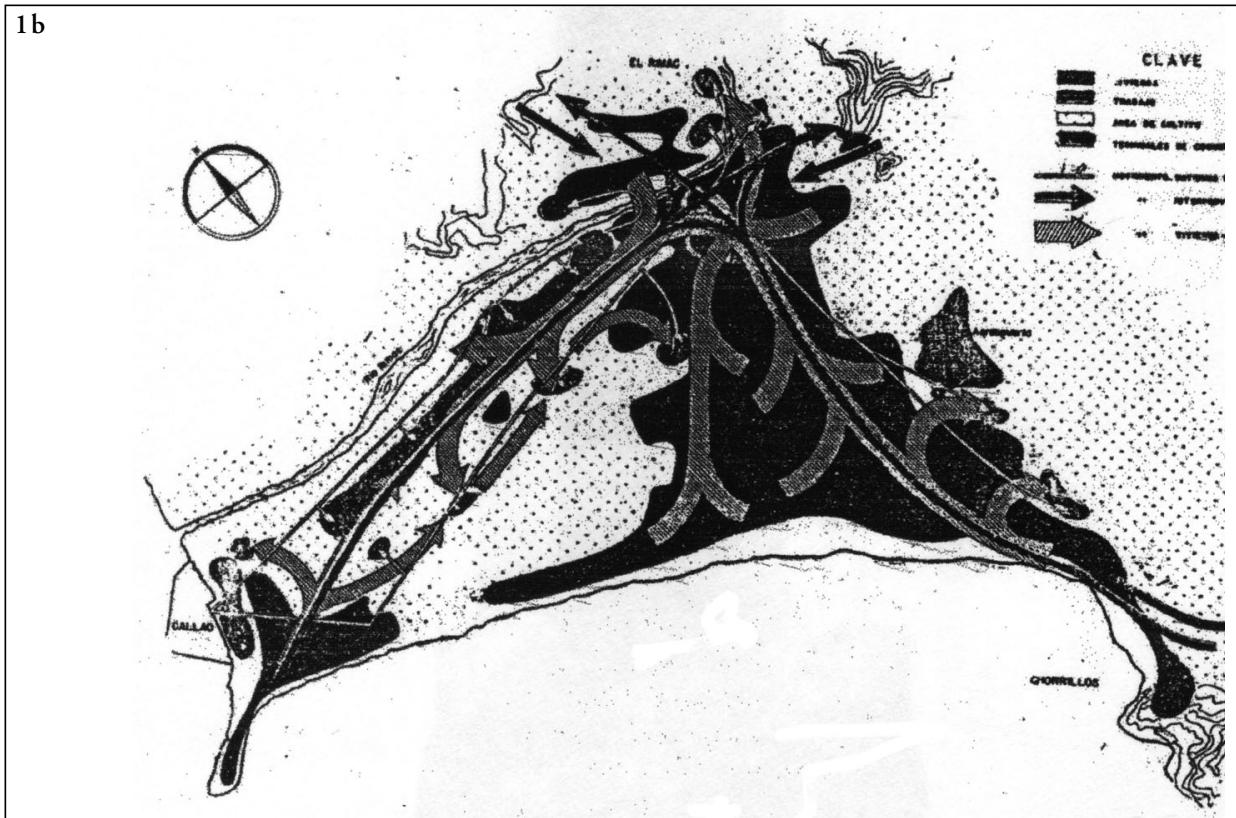

Figura 2. Plan de Desarrollo Metropolitano Lima-Callao a 1980, carátula vol. 3 (Dirección General de Desarrollo Urbano, 1971).

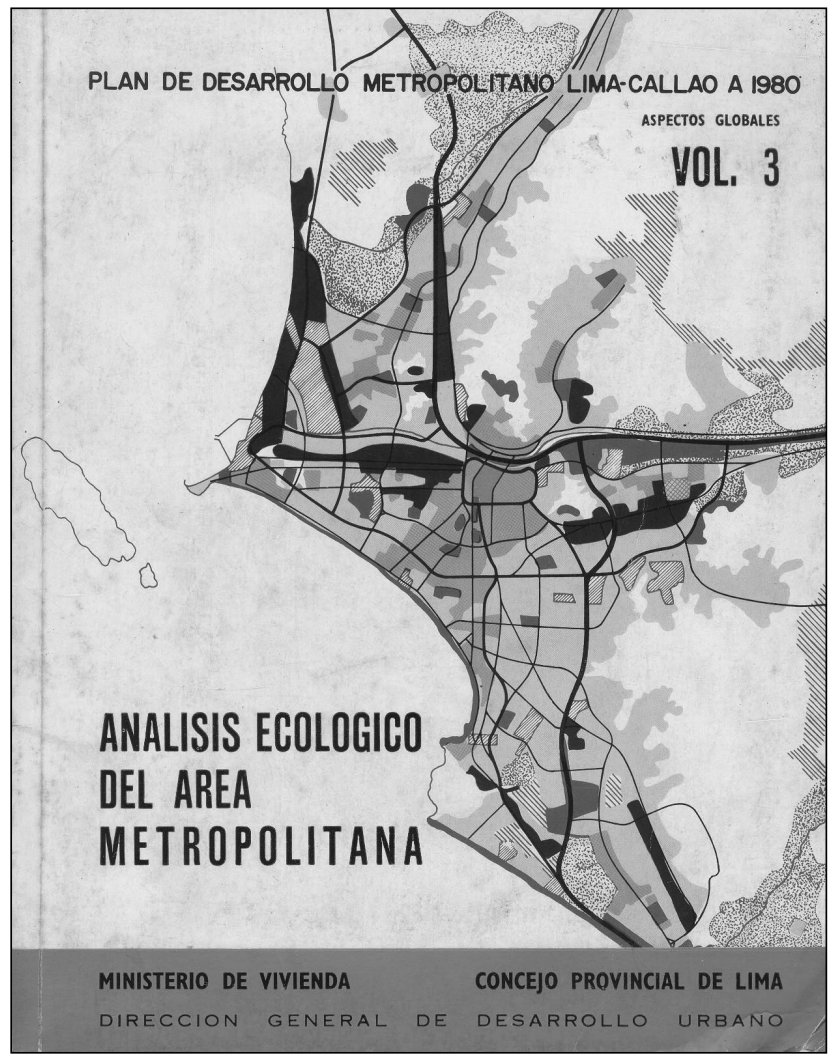


Ciudad y patrones de asentamiento. Estructura urbana y tipologización para el caso de Lima

Figuras 3a y 3b. Barriadas de la Gran Lima: (a) barriadas de la Gran Lima (1957); (b) Matos Mar (1977).
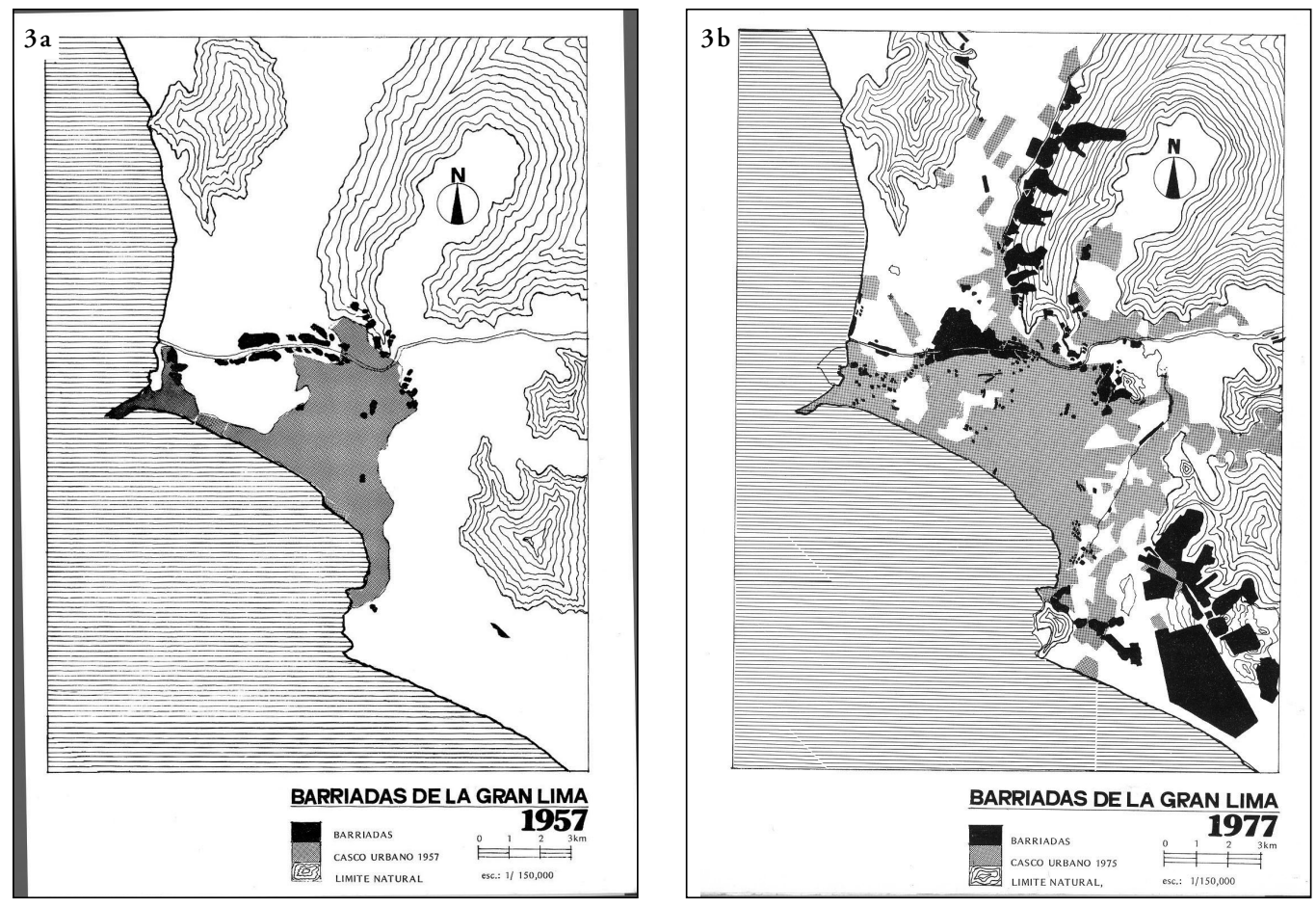

Figura 4. Diferenciación socioespacial en Lima de 1981 (Bähr y Klückmann, 1985).

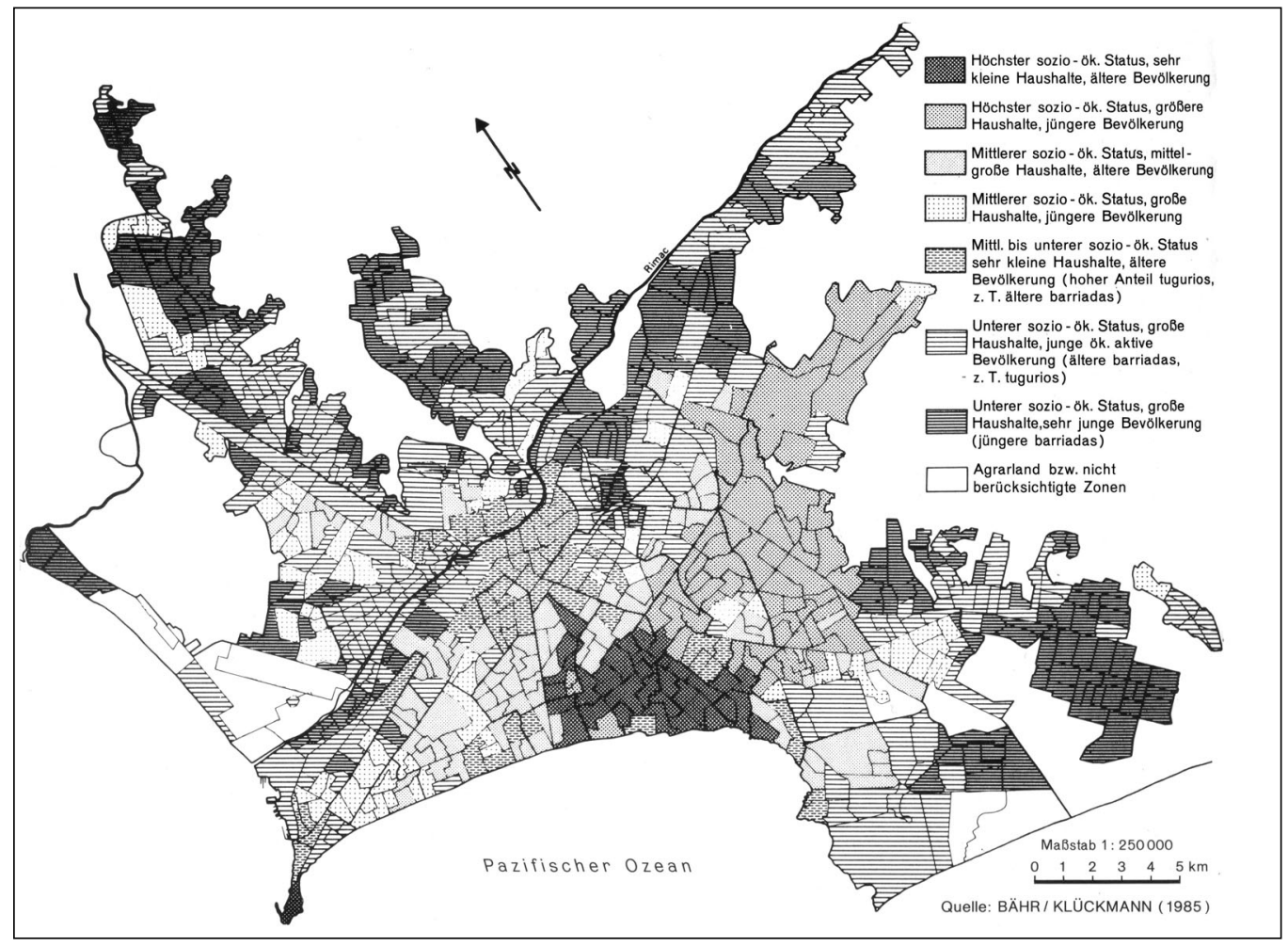


Wiley Ludeña

\section{Referencias bibliográficas}

Alexander, A. (1922). Estudio sobre la crisis de la habitación en Lima. Lima.

Bähr, J. y G. Klückmann (1985). “Sozialräumliche Differenzierung von Wohngebieten unterer Einkommensgruppen in lateinamerikanischen Metropolen: Die Beispiele Santiago de Chile und Lima”. Ibero Amerikanisches Archiv, 11: 283-314.

Bähr, J. y G. Mertins (1995a). "Idealschema der sozialräumliche Differrenzierung lateinamerikanische Grobstädte”. Geographische Zeitschrift, 69: 1-33. Verstädterungsprozesse und Stadtstrukturen. Darmstadt: Wissenschaftliche Buchgesellschaft.

Bähr, J. y A. Borsdorf (2005). "La ciudad latinoamericana. La construcción de un modelo. Vigencia y perspectivas". ur\{b\}es, 2, 2: 7-26.

Caminos, H., J.F.C. Turner y J.A. Steffian (1969). Urban dwelling environments. An elementary survey of settlements for the study of design determinants. Cambridge: The Massachusetts Institute of Technology Press.

Cole, J.P. (1957). Estudio geográfico de la gran Lima. Lima: Oficina Nacional de Planeamiento y Urbanismo.

Córdova, A. (1958). La vivienda en el Perú. Estado actual y evaluación de las necesidades. Lima: Comisión para la Reforma Agraria y la Vivienda.

Chion, M. (1999). The spatial transformation of newly industrializing metropolitan regions in the global context: The case of Metropolitan Lima in the 1990s. Berkeley: Departament of City and Regional Planning, University of California.

Deler, J.P. (1975). Lima 1940-1970. Aspectos del crecimiento de la capital peruana. Lima: Centro de Investigaciones Geográficas.

Delgado, C. (1971). “Tres planteamientos en torno al problema de la urbanización acelerada en áreas metropolitanas: El caso de Lima”. Problemas sociales en el Perú contemporáneo. Lima: Instituto de Estudios Peruanos-Campodónico Ediciones.

Fernández, A.M. (2001). "The diffusion and use of information and communications technologies in Lima, Perú”. Journal of Urban Technology, 8, 3.

Fondo Nacional de Salud y Bienestar Social (1960).
Barriadas de Lima Metropolitana. Lima: Ministerio de Salud y Asistencia Social-Fondo Nacional de Salud y Bienestar Social.

Junta Nacional de la Vivienda (1966). Análisis censal para una evaluación de la vivienda. Lima: Junta Nacional de la Vivienda.

(1967). Obra de la

Junta Nacional de la Vivienda de junio de 1963 a octubre de 1967. Lima: Junta Nacional de la Vivienda-Oficina de Relaciones Públicas.

Krob, E. (1992). Die Barriadas von Lima. Stadtentwicklungsprozesse in einer lateinamerikanischen Metropole. Paderborn: Bochumer Geographische Arbeiten, 55.

Ludeña, W. (2002). "Lima: poder, centro y centralidad. Del centro nativo al centro neoliberal". EURE, Revista Latinoamericana de Estudios Urbanos Regionales, 28, 83: 45-65. (2004). Lima. Historia y urbanismo en cifras. 1821-1970. Tomo 1. Kiel: Kieler Arbeitspapiere zur Landeskunde und Raumordnung, 45/2004.

Matos Mar, J. (1958). "Informe preliminar sobre el estudio de las barriadas marginales”. La Prensa, Lima, 24 de enero.

(1977). Las barriadas de Lima 1957. Lima: Instituto de Estudios Peruanos.

Mantovani, A. (1980). Estudio contextual de la metrópoli limeña. Lima: Universidad Ricardo Palma, Facultad de Arquitectura y Urbanismo.

Meyer-Kriesten, K., J. Plöger y J. Bähr (2004). "Wandel der Stadtstructur in Lateinamerika. Sozial räumliche und funktionale Ausdifferenzierungen in Santiago de Chile und Lima”. Geographische Rundschau, 56, 6: 30-36.

Oficina Nacional de Planeamiento y Urbanismo (1949a). Plan Piloto de Lima. Lima: Oficina Nacional de Planeamiento y Urbanismo.

(1949b). Plan Piloto de Lima. Lima: Universidad Ricardo Palma, Facultad de Arquitectura y Urbanismo.

(1953). Barriadas de los alrededores de Lima. Lima: Oficina Nacional de Planeamiento y Urbanismo.

(1955). Plan Regulador de Lima. Lima: Oficina Nacional de Planeamiento y Urbanismo. 
Ciudad y patrones de asentamiento. Estructura urbana y tipologización para el caso de Lima

(1967). Plan de Desarrollo Metropolitano LimaCallao a 1980. Esquema Director 1967-1980. Lima: Oficina Nacional de Planeamiento y Urbanismo.

Rodríguez, A. y H. Jaworski (1969). "Vivienda en barriadas". Cuadernos DESCO, 4.

Sánchez, A. y J. Calderón (1980). El laberinto de la ciudad. Politicas urbanas del Estado 1950-1979.
Lima: Centro de Estudios y Promoción del Desarrollo.

Sánchez, A., R. Guerrero, J. Calderón y L. Olivera (1979). Tugurización en Lima Metropolitana. Lima: Centro de Estudios y Promoción del Desarrollo.

Tizón y Bueno, R. (1916). El plano de Lima. Apuntaciones históricas y estadisticas. Lima: Imprenta del Centro Editorial. 